\title{
CFD based Computations of Flexible Helicopter Blades for Stability Analysis
}

\author{
Guru P. Guruswamy * \\ Applied Modeling and Simulation Branch \\ NASA Advanced Supercomputing Division \\ NASA Ames Research Center
}

\begin{abstract}
As a collaborative effort among government aerospace research laboratories an advanced version of a widely used computational fluid dynamics code, OVERFLOW, was recently released. This latest version includes additions to model flexible rotating multiple blades. In this paper, the OVERFLOW code is applied to improve the accuracy of airload computations from the linear lifting line theory that uses displacements from beam model. Data transfers required at every revolution are managed through a Unix based script that runs jobs on large super-cluster computers. Results are demonstrated for the 4-bladed UH-60A helicopter. Deviations of computed data from flight data are evaluated. Fourier analysis post-processing that is suitable for aeroelastic stability computations are performed.
\end{abstract}

\section{Introduction}

Accurate aeroelastic computations of helicopter rotor blades involve use of high fidelity fluids and structures models. The flows are often dominated by shocks waves, bladevortex interactions and flow separation and need the use of 3-D Navier-Stokes equations. The primary aeroelastic characteristics of a helicopter rotor blade can be modeled using beam theory.

Several 3-D Navier-Stokes based computational fluid dynamics (CFD) codes are in use today. Among them OVERFLOW is one of the most popular CFD codes for rotorcraft applications. It has been extensively applied for rigid configurations to-date $[1,2,3]$. OVERFLOW uses robust overset structured grids to model the flow field. FUN3D [4] is other similar advanced CFD code based on unstructured grid methodology. Efforts are in

\footnotetext{
* Sr. Scientist, Applied Modeling and Simulation Branch, AIAA Associate Fellow
} 
progress to add aeroelastic capability to OVERFLOW. Recently a 2-D modal [5] and beam finite-element [6] based structures were added for isolated blades with single grid and were demonstrated for cases that do not need trimming. In collaboration with U.S Army engineers[7], NASA added the multi-block-dynamic-deforming grid capability to the latest version $2.1 \mathrm{z}$ of OVERFLOW to compute accurate airloads using the prescribed aeroelastic motions of multiple blades for steady flights[8]. In this effort, OVERFLOW solutions are applied to correct the airloads computed from Comprehensive Analysis (CA) code CAMRAD2 [9] to improve the accuracy of aeroelastic responses.

CAMRAD2 which is similar to UMARC [10] and RCAS [11], computes the airloads using lifting line theory [12] based the displacements from the beam-model of the rotor blade. Results are demonstrated for UH-60A helicopter [13].

\section{Approach}

Accurate computations of airloads for the UH-60A rotorcraft in forward flight requires trim solutions [14]. Current state-of-the art to compute trim is based on lifting line solutions tuned with measured thrust forces [7]. Trim solutions using CFD loads are yet to be developed. In this effort trim parameters are computed using CAMRAD2 which solves the harmonic Hamiltonian equations to give solutions only at the end of each revolution. On the other hand, OVERFLOW is based on a time marching scheme. In order to utilize the trim solutions from CAMRAD2, airloads from OVERFLOW are computed at end of every revolution and applied to correct the airloads of CAMRAD2 which in turn are used for computing the aeroelastic displacements. The structural displacements are computed using the beam finite element solver in CAMRAD2. This approach, which is known as loose coupling (LC), is described step-by-step in the next paragraph.

First a, solution in the form of blade displacement data (known as the motion file for OVERFLOW) is obtained from CAMRAD2 using the flight parameters. The linear lifting line theory along with free wake model is used to compute this initial estimate of motion data from the beam model in CAMRAD2. Assuming steady forward flight, this full-revolution motion data, defined same for all blades, is used as a prescribed motion for OVERFLOW. Using the required time step, computations are made for one 
revolution and aerodynamic forces are computed. These CFD-based aerodynamic loads are used to correct aerodynamic forces in CAMRAD2, and a new motion data file with superimposed trim corrections. The new motion data file is used as a prescribed motion in OVERFLOW to compute corrected aerodynamic forces. The CAMRAD2/ OVERFLOW computations and data corrections are repeated till the results are converged. Convergence of results is established by repeating computations by increasing both number of OVERFLOW/CAMRAD2 iterations and number of time steps per revolution in OVERFLOW.

Figure 1 shows the flow diagram of the OVERFLOW/CAMRAD2 data exchange process. A Unix shell script [15] is used to facilitate the data exchanges between OVERFLOW running on Pleiades super system [16] using Portable Batch System (PBS) [17] with Message Passing Interface (MPI) [18] and CAMRAD running on its front end Linux node. More details along with source of the script will be given in the final paper.

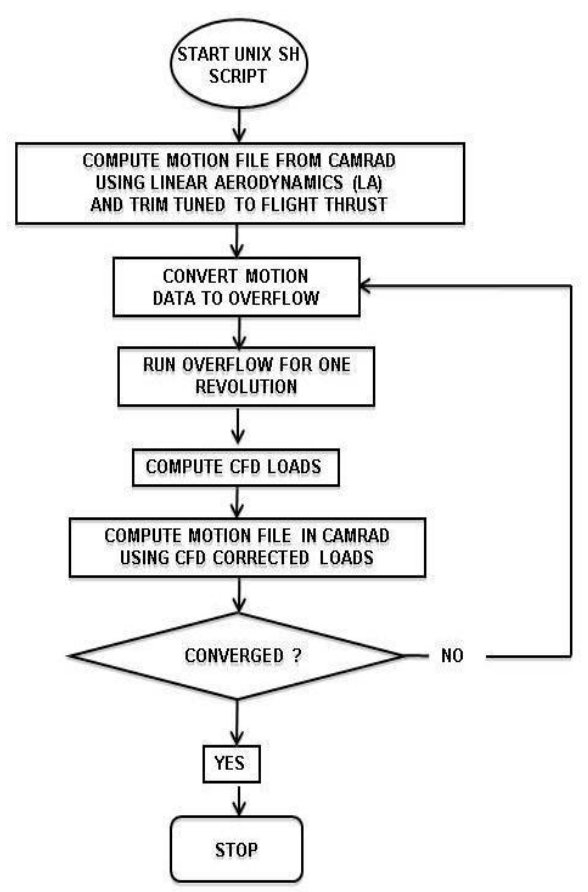

Fig 1. OVERFLOW/CAMRAD2 Data Exchange Process 


\section{Results}

The 4-bladed UH-60A helicopter with its extensive set of flight data [13] is selected for demonstrating the latest version 2.1z of OVERFLOW to correct the airloads and in turn aeroelastic displacements computed from CAMRAD2. Only the rotor blades are

modeled. Each blade has a radius of 322 inches and a chord of 20.76 inch is with a swept tip at $92.9 \%$ radial station. A 5-million point overset grid with 1.9 million near blade grid points is selected. Blade geometry and grid near the tip is shown in Fig. 2. The highspeed test case C8534 [13] that corresponds to a free stream Mach number of 0.236 with an advance ratio of 0.37 and a tip Mach number of 0.642 while blades are rotating a speed of $4.3 \mathrm{~Hz}$ is selected for demonstration.

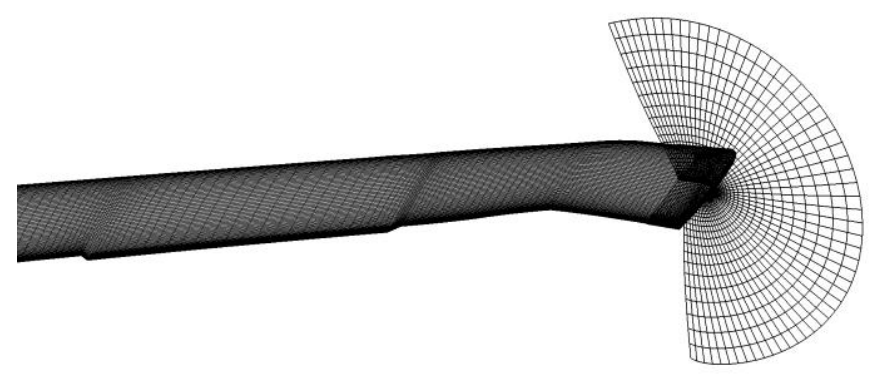

Fig. 2 UH-60A Blade System with Grid near Tip

All computations are made time-accurately by using a constant time-step in OVERFLOW. First, computations are started with 1440 steps per revolution and $\mathrm{CFD} / \mathrm{CSD}$ data exchanges are repeated until the results are converged. Convergence is monitored by tracking the normal force at $86.5 \%$ radial station when the first blade is at 
120 deg azimuth. It required about 25 CFD corrections for convergence. This calculation is repeated by increasing the number of steps per revolution (NSPR) in increments of 1440. Figure 3 shows convergence plots for increasing NSPR. Results converge at about NSPR $=7200$. This is verified by using NSRP $=8640$ which produced result nearly identical with NSPR $=7200$.

Figures 4 and 5 show plots of computed and flight sectional normal force $\mathrm{Cn}$ and pitching moment $\mathrm{Cm}$ for $86.5 \%$ radial station, respectively. The comparisons are favorable. Other sections will be analyzed in the final paper.

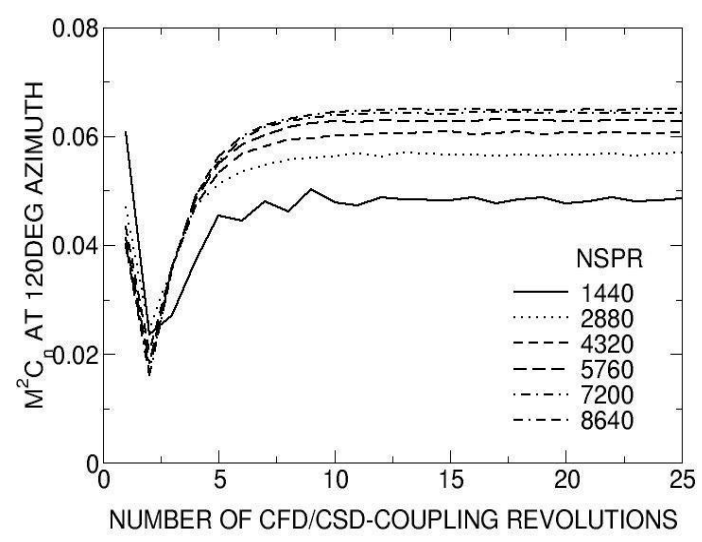

Fig. 3 Convergence of normal force at $86.5 \%$ radial station for the first blade.

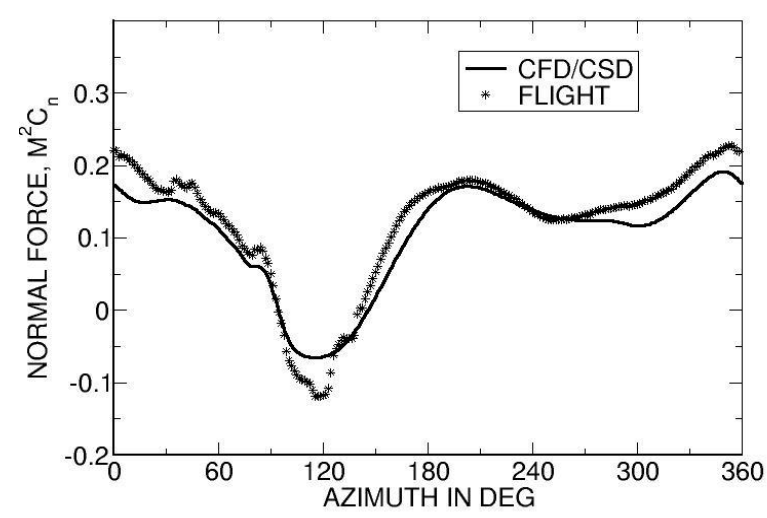

Fig. 4 Comparison of normal force with the flight data at $86.5 \%$ radial station. 


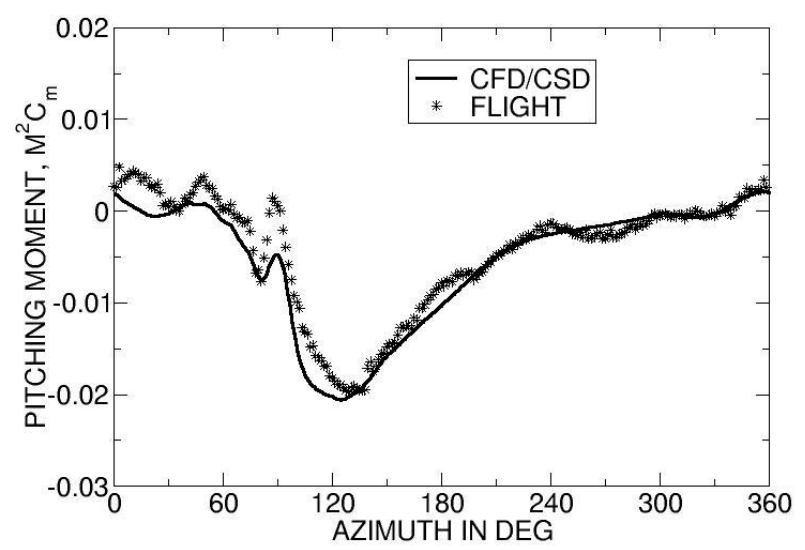

Fig. 5 Comparison of pitching moment with flight data at $86.5 \%$ radial station.

Based on the procedure discussed in Ref. 19, deviations of computed $C_{n}$ and $C_{m}$ from flight data [13] are calculated. Plots of these deviations are shown in Figs. 6 and 7 for $C_{n}$ and $\mathrm{C}_{\mathrm{m}}$, respectively. All computed values are within $10 \%$ of the measured data except for 4 values that go beyond $10 \%$ for $\mathrm{C}_{\mathrm{m}}$. The average deviations are $3.51 \%$ and $3.81 \%$ for $\mathrm{C}_{\mathrm{n}}$ and $\mathrm{C}_{\mathrm{m}}$, respectively. These values are less than the corresponding average deviations, $4.1 \%$, and $4.7 \%$, reported in Ref. 19 based on a survey results taken from literature.

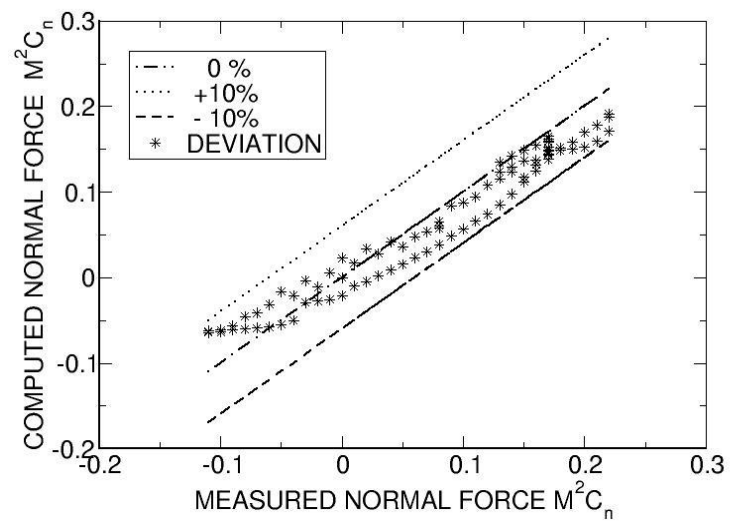

Fig 6. Deviation of computed normal force coefficient from C8534 flight case. 


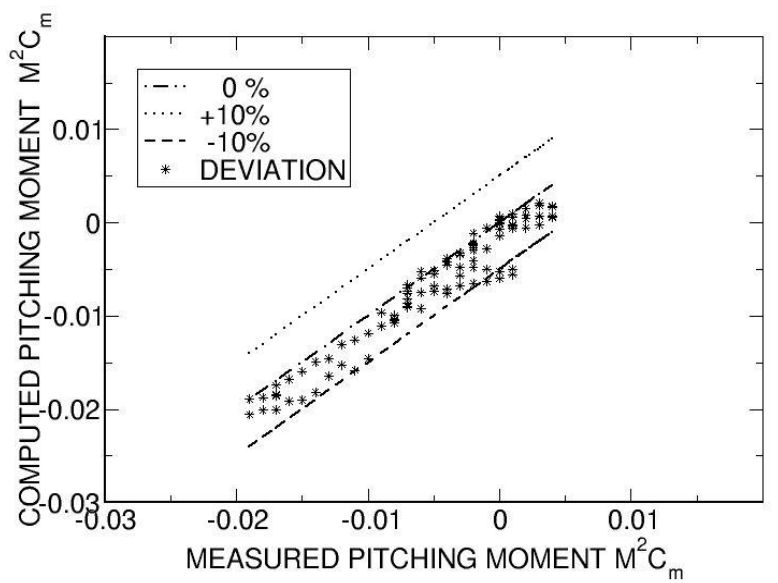

Fig. 7 Deviation of pitching moment from C8534 flight case.

\section{Fourier Transformations for Aeroelastic Stability Analysis}

The aerodynamic forces computed using OVERFLOW need to be converted to Fourier quantities for use in aeroelastic stability analysis [20]. The deviations shown in Figs. 6 and 7 provide information only about magnitude of the airloads. For aeroelastic stability analysis both magnitude and phase angles play an important role. Fourier analysis[21] will also determine the deviations of phase angles from measured data.

Fourier transformations [21] are next applied to the airloads computed from OVERFLOW. Magnitudes and phase angles with respect to azimuth of the first blade are computed for 20 harmonics. Figure 8 shows the comparison between computed and flight normal force magnitude at $r / R=0.865$. The values of magnitude become small after about $9^{\text {th }}$

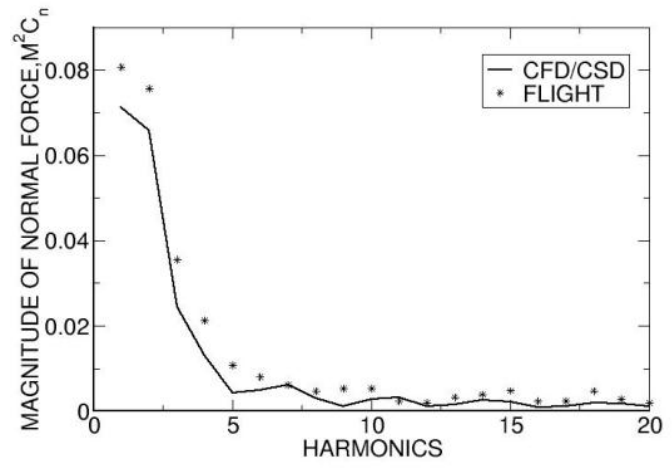

Fig. 8 Comparison of normal force magnitude harmonics at $86.5 \%$ radial station 


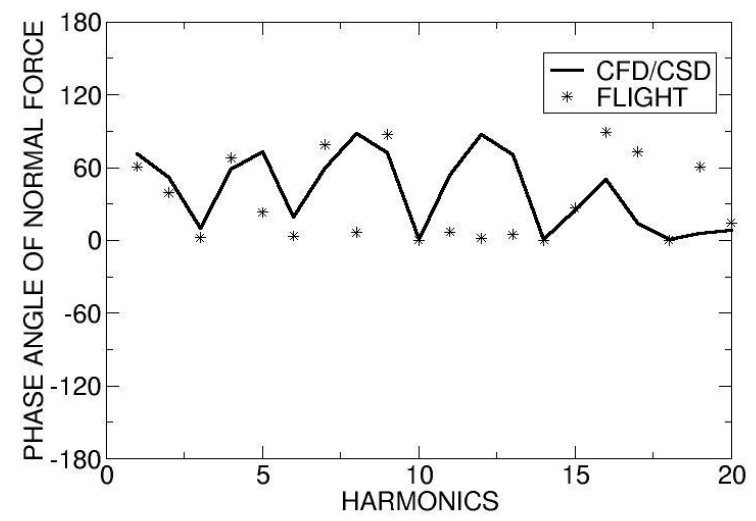

Fig. 9 Comparison of normal force phase angles at $86.5 \%$ radial station.

harmonic. Comparison between computed and measured data is good for all 20 harmonics for magnitude. Figure 9 shows corresponding plots for phase angles. Differences between computed and measured phase angles significantly differ after $4^{\text {th }}$ harmonic. These differences can be attributed to lack of time-accurate couplings between the OVERFLOW and CAMRAD2 computations and also smaller magnitude of loads. Figure 10 show the corresponding comparison of phase angle scaled by the ratio of current magnitude to the magnitude of the first harmonic. This plot shows good a comparison for all harmonics.

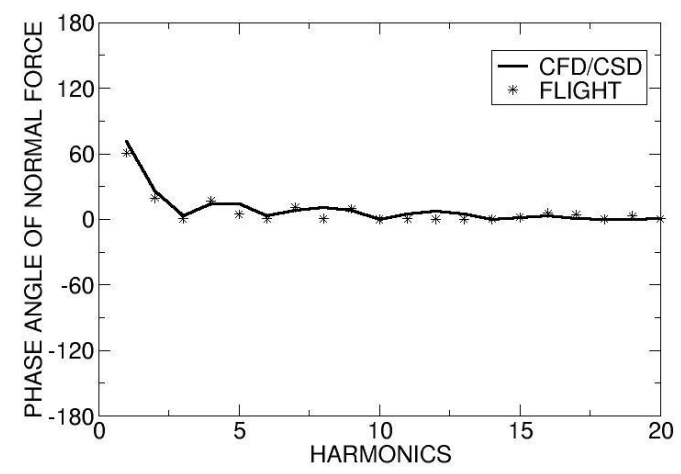

Fig. 10 Comparison of scaled phase angles of normal force at $86.5 \%$ radial station 
Figure 11 shows a comparison of magnitude between computed and flight pitching moment magnitude at $\mathrm{r} / \mathrm{R}=0.865$. The pitching moment magnitude becomes small for higher harmonics. Comparison between computed and measured data is good for all 20 harmonics except for some discrepancies around $5^{\text {th }}$ harmonic.

Figure 12 shows the plot of computed and measured phase angles for the pitching moment. Difference between computed and measured phase angles are more significant after the $3^{\text {rd }}$ harmonic. Figure 13 shows phase angle the comparison scaled by the ratio of current magnitude to magnitude of the first harmonic. The scaled values show good comparison for all harmonics.

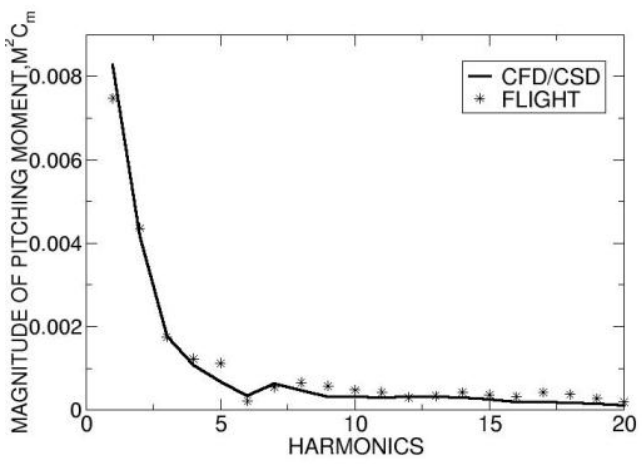

Fig. 11 Comparison pitching moment magnitude at the $86.5 \%$ radial station

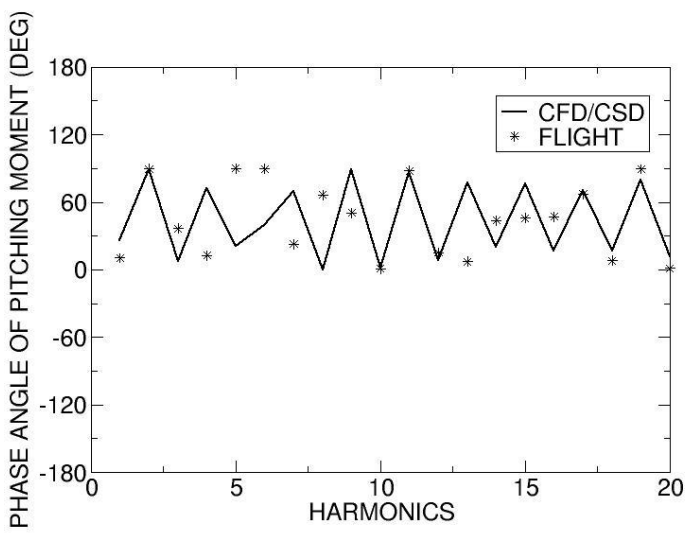

Fig. 12 Comparison pitching moment phase angles at $86.5 \%$ radial station. 


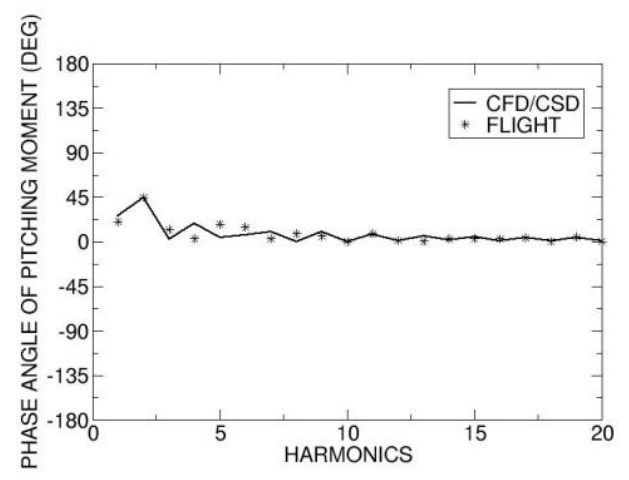

Fig. 13 Comparison of scaled of pitching moment phase angles at the $86.5 \%$ radial station

\section{Conclusions}

Computations are made in the paper to demonstrate the use of advanced CFD codes for aeroelastic stability analysis of helicopter blades. A procedure to measure the deviation of computed data from flight test data is presented. More details about the coupling procedure and the Fourier analysis of the data will be discussed in the full paper. A procedure to use Fourier coefficients to compute the aeroelastic stability boundary will be discussed in the full paper. It will be based on the procedure developed in Ref. 22 for computing the stability boundary by using the Fourier Coefficients of unsteady aerodynamic data from Transonic Small Perturbation theory.

\section{Acknowledgements}

Author would like to thank Mark Potsdam of U.S Army, Pieter Buning and Doug Boyd of Langley Research Center for providing valuable help during this work. Discussions with Neal Chaderjian, Jasim Ahmad and Tom Pulliam of NASA Ames Research Center on comparisons of computed data with the flight data were helpful. Special thanks to Dennis Jesperson and Ethan Romander of Ames Research Center for providing consultations on using super cluster and CAMRAD2, respectively. The guidance of Terry Holst, NASA Subsonic Rotary Wing project's CFD lead, was highly valuable through-this effort. 


\section{References}

1. Meakin, R., "Unsteady Simulation of the Viscous Flow about a V-22 Rotor and Wing in Hover," AIAA-95-3463-CP, AIAA Atmospheric Flight Mechanics Conference, Baltimore, MD, August 1995.

2. Potsdam M., Pulliam, T. H., "Turbulence Modeling Treatment for Rotocraft Wakes," Presented at AHS Aeromechanics Specialist's Meeting, San Francisco, CA, Jan. 23-25, 2008.

3. Holst, T. and Pulliam, T.H., "Overset Solution Adaptive Grid Approach Applied to Hovering Rotorcraft Flows," AIAA-2009-3519, 27th AIAA Applied Aerodynamics Conference, San Antonio, Texas, June 2009.

4. Biedron B. and Thomas, J., " Recent Enhancements to the FUN3D flow solver for Moving Mesh Applications," AIAA-2009-1360, June 2009.

5. Guruswamy, G.P.,"A Modular Approach to Euler/Navier-Stokes-Based Aeroelasticity of Helicopter Rotor Blades," AIAA-2008-2179, 49th AIAA/AHS Structural Dynamics Conf, Chicago, April 2008.

6. Guruswamy, G.P, "CFD/CSD Based Aeroelastic Computations of Helicopter Blades Using a Modular Approach," AIAA-2009-4199, 39th AIAA Fluid Dynamics Conf., San Antonio, Texas, June 2009.

7. Potsdam, M., Yeo, H. and Johnson,W. "Rotor Airloads Using Loose Aerodynamic /Structural Coupling," American Helicopter Society $60^{\text {th }}$ Annual Form, Baltimore, MD, June 2004

8. Boyd, D. D, "HART-II Acoustic Predictions using a Coupled CFD/CSD methods," American Helicopter Society 65th Annual Forum, Grapevine Texas, May 2009.

9. Johnson, W., "Rotorcraft Aerodynamic Models for a Comprehensive Analysis," American Helicopter Society, 54 ${ }^{\text {th }}$ Annual Form, Washing ton D. C, May 1998.

10. Datta, A., and Chopra, I., "Validation and Understanding of UH-60A Vibratory Loads in Steady Level Flight," Journal of the American Helicopter Society, Vol. 49, (3), July 2004, pp. 271-287. 
11. RCAS Anon. RCAS Theory Manual, Version 2.0. Technical Report USAMCOM/AFDD TR 02-A-005, US Army Aviation and Missile Command, Moffett Field, CA, June 2000.

12. Gessow, M., "The Aerodynamics of the Forward Flight" Aerodynamics of the Helicopter, Fedrick Ungar Publishing, Co, New York, 1967, pp 180-216.

13. Kufeld, R. M., Balough, D. L., Cross, J. L., Studebaker, K.F., Jenninson, C. D. and Bousman, W. G," Flight Testing of the UH-60A Airloads Aircraft," American Helicopter Society, 50 ${ }^{\text {th }}$ Annual Forum, Washington DC, May 1994.

14. Peters, D. A. and Barwey, D., "A general theory of rotorcraft trim," Mathematical Problems in Engineering, Volume 2 (1996), Issue 1, pp 1-34.

15. Robbins, A., Beebe, N. H. F, Classic Shell Scripting, O'Reilly Media Inc, 2005, Sebastopol, CA.

16. Guruswamy, G. P, "Large-Scale Computations for Stability Analysis of Launch Vehicles Using Cluster Computers" AIAA 2010-2954, $52^{\text {nd }}$ AIAA/AHS/ Structural Dynamics and Materials conference, Orlando, FL, April, 2010.

17. Stanzione D., "LSF/PBS Scripting Nuts and Bolts," Cluster World, Vol. 2 No 7, July 2004.

18. Groop, W., Lusk, E., and Skjellum, A., Using MPI - Portable Parallel Programming with the Message Passing Interface, Scientific and Engineering Computing Series. 1999, the MIT Press, Cambridge, Massachusetts.

19. Holst, T.L., Lee-Rausch, M., Biedron, R. T, Guruswamy, G.P., and Kreeger, R. E "Chapter-4 Computational Fluid Dynamics, A Status of NASA Rotorcraft Research," edited by Yamauchi G. K and Young, L. A, NASA/TP-2009215369, Sept 2009, pp. 149-192.

20. Krodkiewski, J.M., "Stabilization of Motion of Helicopter Blades Using Delayed Feedback- Modeling, Computer Simulation and Experimental Verification," Jl of Sound and Vibration, (2000) 234(4) pp. 591-610.

21. Kreyszig, E, "Fourier Analysis", Advanced Engineering Mathematics, John Wiley \& Sons, Inc., Hoboken, NJ, 1976, pp. 478- 529.

22. Guruswamy, P. and Yang, T.Y., "Aeroelastic Time Response of Thin Airfoils by Transonic Code LTRAN2,"International Journal of Computers and Fluids, Vol. 9, 